УДК 614.84

A. A. Чернуха, к.т.н., доч. каф. (ORCID 0000-0002-0365-3205)

П. А. Ковальов, к.т.н., дочент, нач. каф. (ORCID 0000-0002-2817-5393)

О. . Безуглов, к.т.н., дочент, доч. каф. (ORCID 0000-0002-8619-9174)

Начіональний університет цивільного захисту Украӥни, Харків, Украйна

\title{
АНАЛІЗ ЯКОСТІ ЗАСТОСУВАННЯ ПРОСОЧУВАЛЬНОГО ВОГНЕЗАХИСНОГО ЗАСОБУ ДСА ДЛЯ ДЕРЕВИНИ ДУБУ
}

Проведено експериментальні дослідження вогнезахисної ефективності засобу ДСА для деревини дубу. Отримано залежність вогнезахисної ефективності від маси сухого засобу, що нанесено, що важливо при обробці засобом ДСА деревини дубу. Досліджений вплив особливостей деревини різних порід на ефективність вогнезахисних просочувальних засобів на прикладі дубу та засобу ДСА. Встановлено, що стандартний метод досліджень вогнезахисної ефективності з використанням виключно сосни не може надати справедливі дані, щодо ефективності засобу до інших порід деревини. Так, згідно інструкції засобу, що випробуваний, необхідно 3 нанесення, але для дубу для досягнення I-ої групи вогнезахисної ефективності знадобилось 7 нанесення. Після виконання дослідження вогнезахисної ефективності ДСА передбачене в нормах на прикладі обробки деревини дубу, можна проаналізувати вогнезахист інших порід деревини. Під час попередніх досліджень вже отримані вогнезахисні характеристики основних вогнезахисних засобів для деяких порід деревини. Породи деревини з великою питомою масою мають погану просочуваність в наслідок чого необхідна більша кількість обробок для досягнення I-ої групи вогнезахисної ефективності за ГОСТ 16363. Отримана залежність втрати маси обробленого зразка деревини від кількості вогнезахисного складу при стандартних випробуваннях надає можливість інженерного, економічного та інших розрахунків при виконанні робіт щодо вогнезахисту. Перевірено стандартний метод досліджень вогнезахисної ефективності з використанням виключно сосни. Визначено, що стандартні методи випробувань не можуть бути об'єктивними при обробці інших порід крім сосни. Особливо корисною для дослідження $є$ залежність втрати маси обробленого зразка деревини від кількості вогнезахисного складу при стандартних випробуваннях, вплив особливостей деревини різних порід на ефективність вогнезахисних просочувальних засобів на прикладі дубу та засобу ДСА. Дуб має більшу питому вагу ніж сосна, тому внести достатню кількість діючої речовини більш складна задача.

Ключові слова: вогнезахист, вогнезахисна ефективність, вогнезахисне покриття, просочування, експериментальні дослідження

\section{1. Ветуп}

Одним із способів вогнезахисту є просочування. При локальному впливі короткочасного джерела запалювання вогнезахисні покриття ускладнюють горіння дерев'яних конструкцій, полегшують гасіння пожежі, а в ряді випадків виключають можливість його виникнення.

У більшості вогнезахисних засобів їх ефективність залежить від кількості обробок, нанесення на поверхню, що захищається. Виробник визначає кількість обробок вогнезахисним засобом для досягнення певної групи вогнезахисної ефективності спираясь на сертифікаційні випробування. Для ДСА ця кількість досягає 3. При сертифікаційних випробуваннях використовується деревина сосни. Різні породи деревини мають різні властивості щодо горіння, просочення, термодеструкції. Таким чином забезпечення нормативної вогнестійкості дерев'яних конструкцій є актуальною науковою проблемою.

\section{2. Аналіз літературних даних та постановка проблеми}

Вогнезахист деревини просочуванням здійснюється двома методами методом поверхневого нанесення [1], не достатньо розкрита проблема обробки різних порід деревини, і методом глибокого просочення [2], не розглянуто 
просочення різними вогнезахисними засобами. При застосуванні вогнезахисних просочувальних засобів кількість обробок для досягнення I-ої групи вогнезахисної ефективності складає 3-4 [3], це визначено для деревини сосни, що не може бути використано для інших порід деревини. Метод глибокого просочення доцільно застосовувати для попередньої обробки вихідної деревини або виробів 3 деревини невеликих розмірів [4], не розглянута можливість використання методи на стадії експлуатації об’єкту. Метод поверхневої обробки застосовують для обробки будівельних конструкцій як перед монтажем [5], не розглянута можливість відновлення вогнезахисту при його втраті під час експлуатації. Хоча метод глибокого просочення забезпечує більш високий рівень вогнезахисту [6], проте він значно більш трудомісткий у порівнянні з методом поверхневого просочення. Поверхневе просочення [7], потребує додаткового вивчення в залежності від породи деревини.

Деревина, оброблена просочувальними складами, зберігає свою фактуру, що робить іiі затребуваною у випадках, якщо висуваються високі вимоги до декоративних характеристикам виробів 3 деревини. Речовини, які в результаті введення в деревину зменшують іiі горючість, називають - антипірени. Дія антипіренів на процес горіння деревини пояснюється такими механізмами:

- речовини, введені в деревину поглинають тепло на свій нагрів і термічний розклад;

- газоподібні негорючі продукти термічного розкладання антипіренів розбавляють горючі гази в просторі над деревиною;

- в результаті термодеструкції антипіренів утворюються інгібітори реакцій, що протікають в зоні горіння над поверхнею деревини;

- антипірени змінюють механізм реакцій термодеструкції деревини в бік утворення негорючих газоподібних продуктів $\left(\mathrm{CO}_{2}, \mathrm{H}_{2} \mathrm{O}\right)$ i пористого поверхневого карбонізованого шару [8], не розглянута втрата несучої спроможності конструкції в наслідок активного, каталітичного провуглення провуглення карбонізованого шару;

- запобігання реакції гетерогенного горіння шляхом ізоляція поверхні вуглецевого шару від кисню повітря [9], що не достатньо ефективно.

Використання неорганічних речовин для вогнезахисту, отримання ефективного покриття [10] має високу ефективність вогнезахисту, але потребує всебічної перевірки експлуатаційних властивостей, як на стадії використання так і під час термічного впливу на поверхню, що захищається.

Таким чином, невирішеною частиною розглянутої проблеми $є$ забезпечення нормативної вогнестійкості дерев'яних конструкцій із деревини дубу за допомогою вогнезахисного засобу ДСА.

\section{3. Мета та завдання дослідження}

Метою роботи є аналіз можливості застосування вогнезахисного засобу ДСА для обробки деревини дубу.

Для досягнення мети необхідно вирішення наступних завдань:

- експериментально визначити ефективність вогнезахисного засобу ДСА для різної кількості обробок деревини дубу;

- отримати залежність ефективності вогнезахисного засобу ДСА від кількості сухого складу. 


\section{4. Визначення вогнезахисної ефективності засобу}

Для цього були проведені експериментальні дослідження. Метод випробувань ГОСТ 16363-98 "Засоби вогнезахисні для деревини. Методи визначення вогнезахисних властивостей" встановлює класифікаційний метод i метод прискорених випробувань для визначення групи вогнезахисної ефективності засобу.

Суть прискореного методу випробувань полягає у впливі полум'я пальника із заданими параметрами (температура газоподібних продуктів горіння на виході 3 керамічної труби становить $200\left(\mathrm{C} \pm 5^{\circ} \mathrm{C}\right)$ на зразок деревини з вогнезахисним покриттям або просоченням, який розміщений в керамічної трубі установки ОТМ, в умовах, які сприяють акумуляції тепла, і визначенні втрати маси цим зразком деревини після вогневих випробувань [10].

Устаткування для випробувань і засоби вимірювальної техніки:

- випробування проводилися на базі приладу ОТМ, купол розташований на 40 ( \pm 2 ) мм вище керамічного короба;

- мікропроцесорний модуль «TRITON 6000»;

- комп'ютер на базі процесора AMD, програмного забезпечення Windows, Termosoft;

- сушку зразків проводили в сушильній шафі СНОЛ-3,5.3, 5.3,5 - И1 (ТУ 16681.032-84).

Випробування проводять на трьох зразках. Зразок тримають у полум'ї пальника протягом 2 хвилин. Через 2 хвилини подачу газу припиняють i залишають зразок в приладі для охолодження до кімнатної температури. Охолоджений зразок дерева виймають $з$ керамічного короби і зважують.

Втрату маси зразка Р в процентах розраховують за формулою:

$$
P_{i}=\frac{\left(m_{1}-m_{2}\right) \cdot 100}{m_{1}}, \%
$$

де $\mathrm{m}_{1}$ - маса зразка до випробування, $г$; $\mathrm{m}_{2}$ - маса зразка після випробувань, г.

За результат випробувань приймають середнє арифметичне трьох випробувань.

Залежно від величини втрати маси зразків, визначеної за класифікаційними методом випробувань, вогнезахисне покриття або просочувальний засіб належать до таких груп вогнезахисної ефективності (табл. 1)

Табл. 1. Класифікація груп вогнезахисної ефективності згідно ГОСТ 16363-98

\begin{tabular}{|c|c|}
\hline Втрата маси, \% & Групи вогнезахисної ефективності \\
\hline Не більше 9 & I \\
\hline Більше 9, але менше 25 & II \\
\hline
\end{tabular}

Типи зразків, що досліджено - деревина дубу оброблена ДСА від 3 до 5 разів.

При дослідженні наведених зразків нами обрано середні значення наведені в протоколах випробувань, таким чином для кожного типу зразка, параметри випробувань приведені як середнє арифметичне трьох випробувань.

Данні дослідження зразків дуб-ДСА наведено в табл. 2.

3 графіків наведених на рис. 1 бачимо, що процент втрати маси зразка значно зменшується при введені більшої кількості сухої суміші вогнезахисного 
засобу, але мінімальна кількість просочувань для досягнення першої групи вогнезахисної ефективності складає 4.

3 графіків наведених на рис. 1 бачимо, що процент втрати маси зразка значно зменшується при введені більшої кількості сухої суміші вогнезахисного засобу, але мінімальна кількість просочувань для досягнення I-ої групи вогнезахисної ефективності складає 6.

Табл. 2. Втрата маси та витрата сухого складу в залежності від кількості обробок для деревини дубу обробленої ДСА

\begin{tabular}{|c|c|c|c|c|c|c|c|c|c|}
\hline \multirow[b]{2}{*}{ 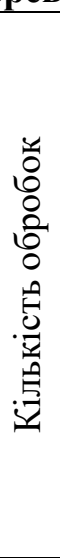 } & \multirow[b]{2}{*}{ 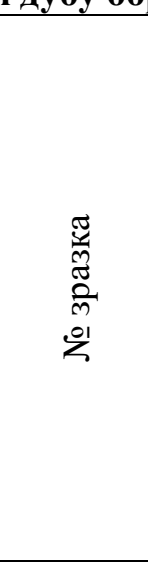 } & \multicolumn{3}{|c|}{ Маса зразка, г } & \multirow[b]{2}{*}{ 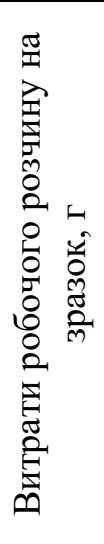 } & \multirow[b]{2}{*}{ 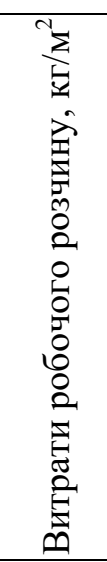 } & \multirow[b]{2}{*}{ 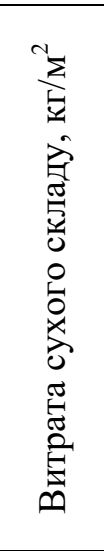 } & \multirow[b]{2}{*}{ 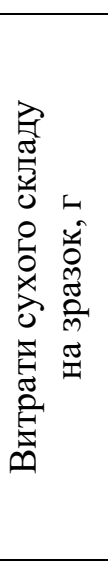 } & \multirow[b]{2}{*}{ 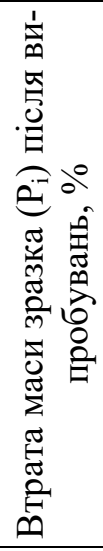 } \\
\hline & & 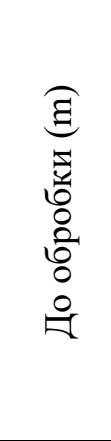 & 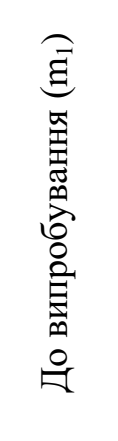 & 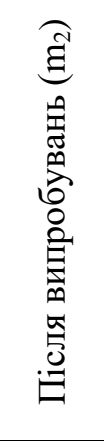 & & & & & \\
\hline \multirow{4}{*}{4} & 1 & 197,8 & 200,4 & 165,0 & 6,1 & 0,199 & 0,085 & 2,6 & 17,7 \\
\hline & 2 & 183,8 & 186,3 & 141,6 & 5,8 & 0,190 & 0,082 & 2,5 & 24,0 \\
\hline & 3 & 207,0 & 209,6 & 167,7 & 6,0 & 0,196 & 0,085 & 2,6 & 20,0 \\
\hline & середнє & 196,2 & 198,8 & 158,1 & 6,0 & 0,195 & 0,084 & 2,6 & 20,5 \\
\hline \multirow{4}{*}{5} & 4 & 210,1 & 213,1 & 187,6 & 7,4 & 0,242 & 0,098 & 3,0 & 12,0 \\
\hline & 5 & 213,0 & 216,0 & 192,1 & 7,2 & 0,235 & 0,098 & 3,0 & 11,1 \\
\hline & 6 & 206,5 & 209,6 & 181,1 & 7,0 & 0,229 & 0,101 & 3,1 & 13,6 \\
\hline & середнє & 209,9 & 212,9 & 186,9 & 7,2 & 0,235 & 0,099 & 3,0 & 12,2 \\
\hline \multirow{4}{*}{6} & 7 & 212,3 & 215,7 & 198,5 & 8,5 & 0,278 & 0,111 & 3,4 & 8,0 \\
\hline & 8 & 187,2 & 190,8 & 174,0 & 8,3 & 0,271 & 0,118 & 3,6 & 8,8 \\
\hline & 9 & 210,7 & 214,2 & 197,3 & 8,8 & 0,288 & 0,114 & 3,5 & 7,9 \\
\hline & середнє & 203,4 & 206,9 & 189,9 & 8,5 & 0,279 & 0,114 & 3,5 & 8,2 \\
\hline
\end{tabular}

5. Визначення залежності вогнезахисної ефективності засобу від кількості сухого вогнезахисного засобу

При розрахунку фактичних витрат вогнезахисного складу для досягнення необхідного ступеню вогнезахисної ефективності, побудована залежність відсоткової втрати маси зразка при стандартних випробуваннях.

Вираз (2) виражає процент втрати маси зразком деревини дубу при стандартних випробуваннях в залежності від маси сухої речовини витраченої на обробку зразка. Достовірність апроксимації $\mathrm{R}^{2}=1$.

$$
\mathrm{P}_{\mathrm{i}}=9,995 \cdot \mathrm{m}_{\mathrm{cc}}{ }^{2}-73,84 \cdot \mathrm{m}_{\mathrm{cc}}+144,2, \%
$$

де $\mathrm{P}_{\mathrm{i}}$ - втрата маси зразка, \%; $\mathrm{m}_{\mathrm{cc}}-$ маса сухого складу, г.

Для ефективного практичного використання засобу безумовно має велике значення кількість обробок. Від цієї характеристики залежить ціна обробки, кількість складу, час проведення робіт. 


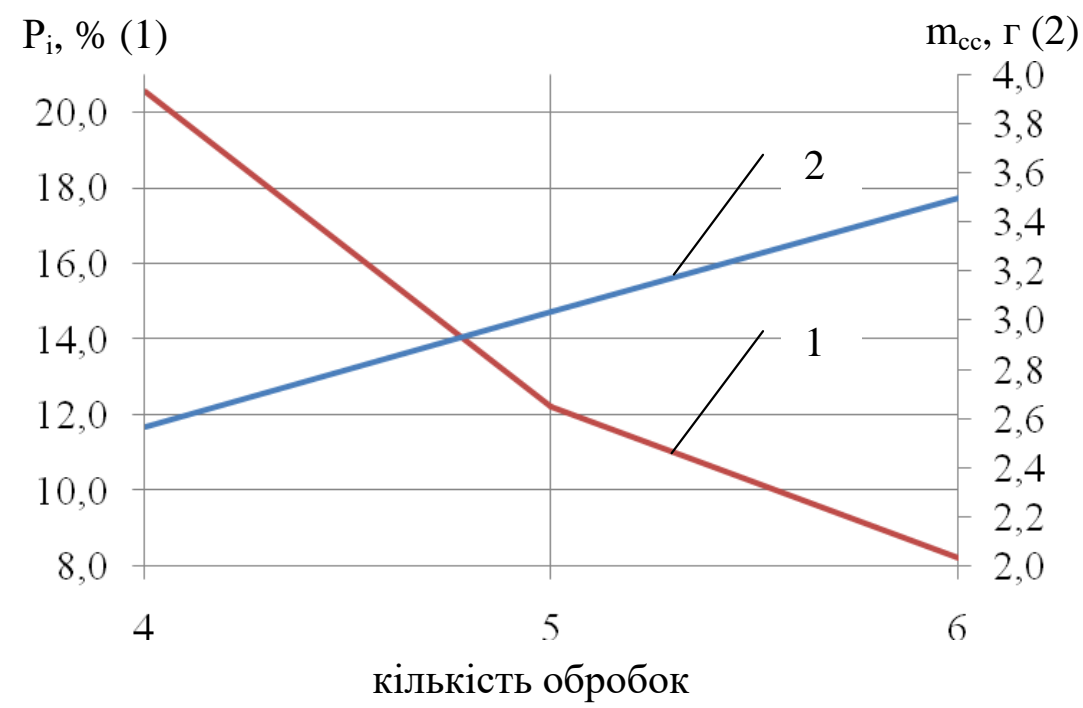

Рис. 1. Втрата маси та витрата сухого складу в залежності від кількості обробок для дубу обробробленої ДСА: 1 - втрата маси; 2 - витрата сухого складу

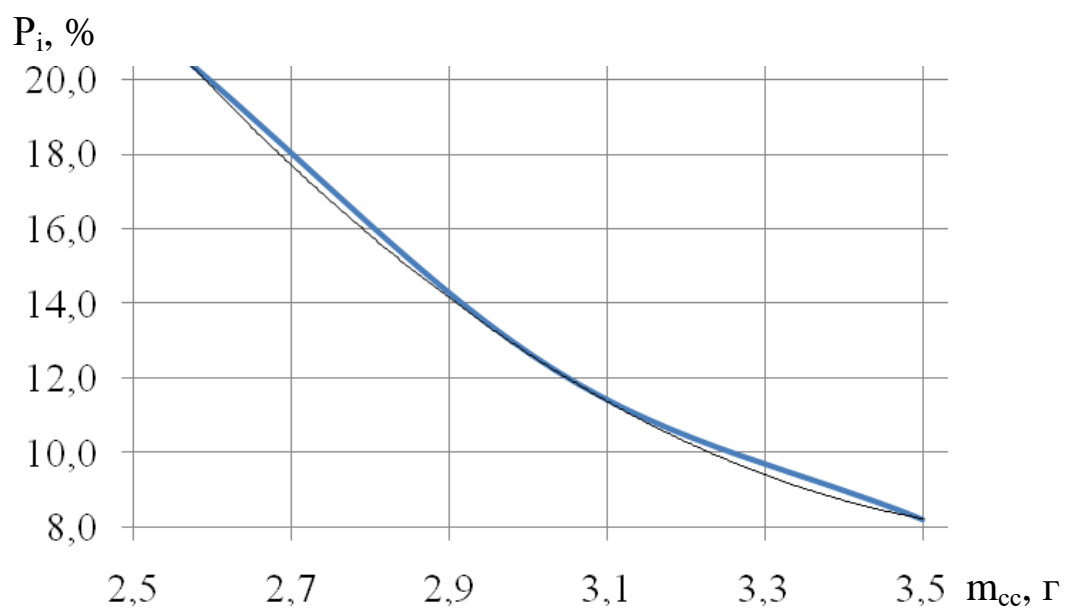

Рис. 2. Втрата маси зразка в залежності від витрати сухого складу

Але при розрахунку необхідної кількості матеріалу для обробки необхідно розраховувати масу сухого засобу.

\section{6. Обговорення результатів дослідження вогнезахисного засобу}

В наслідок аналізу існуючих методів вогнезахисту, методики сертифікації було встановлено, що для встановлення ефективності вогнезахисту засобу використовується деревина сосни. При встановлені вогнезахисної ефективності засобу для деревини дубу виявилось, що кількості обробок згідно інструкції не достатньо для отримання першої групи вогнезахисної ефективності. При визначенні вогнезахисної ефективності було досліджено втрату маси та витрату сухого складу в залежності від кількості обробок для деревини дубу. Результати дослідження представлені в табл. 2 по три зразка на кожну кількість обробок. Результатти дослідження графічно представлені на рис. 1.

Після виконання дослідження вогнезахисної ефективності ДСА передбачене в нормах на прикладі обробки деревини дубу, можна проаналізувати вогнезахист інших порід деревини. Під час попередніх досліджень вже отримані вогнезахисні характеристики основних вогнезахисних засобів для деяких порід деревини. Породи деревини 3 великою питомою масою мають погану просочуваність в Civi1 security. DOI: $10.52363 / 2524-0226-2021-33-19$ 
наслідок чого необхідна більша кількість обробок для досягнення I-ої групи вогнезахисної ефективності за ГОСТ 16363.

Отримана залежність втрати маси обробленого зразка деревини від кількості вогнезахисного складу при стандартних випробуваннях (рис. 2) надає можливість інженерного, економічного та інших розрахунків (2) при виконанні робіт щодо вогнезахисту. Перевірено стандартний метод досліджень вогнезахисної ефективності з використанням виключно сосни. Визначено, що стандартні методи випробувань не можуть бути об'єктивними при обробці інших порід крім сосни.

Результати роботи необхідні для оцінки необхідної обробки деревини дубу, розрахунку кількості сухого засобу та кількості обробок для досягнення першої групи вогнезахисної ефективності.

Подальший розвиток роботи полягає в більш детальному дослідженні кількісних характеристик обробки, надання рекомендацій та методики розрахунку корекції інструкції з нанесення вогнезахисних засобів в залежності від виду деревини, що обробляється.

\section{7. Висновки}

1. Експериментально визначено вогнезахисну ефективність засобу при різної кількості обробок. Досліджений вплив особливостей деревини на ефективність вогнезахисних просочувальних засобів на прикладі дубу та засобу ДСА. Вивчено залежність вогнезахисної ефективності засобу від кількості обробок. Встановлено, що стандартний метод досліджень вогнезахисної ефективності 3 використанням виключно сосни не може надати справедливі дані, щодо ефективності засобу до інших порід деревини. Так, згідно інструкції засобу, що випробуваний, необхідно 3 нанесення, але для дубу для досягнення I-ої групи вогнезахисної ефективності знадобилось 7 нанесень.

2. Отримано залежність вогнезахисної ефективності від кількості сухого вогнезахисного засобу, що має практичне значення для фактичного розрахунку необхідної кількості ДСА на площу поверхні, що захищається. Так визначено, що при виконанні нормативної обробки у кількості 3 нанесень, втрата маси зразку перевищує 12 \%, що не задовольняє навіть II-ій групі вогнезахисної ефективності, формально така деревина не вважається вогнезахищенною. Фактична кількість вогнезахисного складу для отримання достатнього вогнезахисту значно перевищує нормативну. Так за інструкцією витрачається близько 0,196 кг сухого складу на $1 \mathrm{~m}^{2}$ поверхні, що захищається а для досягнення втрати маси після випробування менше $9 \%$ необхідно витратити близько 0,279 кг на $1 \mathrm{~m}^{2}$ поверхні. Таким чином, для отримання I-ої групи вогнезахисної ефективності для деревини дубу необхідно в 2,3 рази більше сухого засобу ніж передбачено інструкцією.

\section{Література}

1. Чернуха А. А., Киреев А. А., Бондаренко С. Н., Кириченко А. Д. Исследование огнезащитной эффективности покрытий на основе ксерогелевой композиции // Пожежна безпека. 2009. № 26. С. 166-171. URL: http://repositsc.nuczu.edu.ua/handle/123456789/4551

2. Kireev A., Tregubov D., Safronov S., Saveliev D. Study insulating and cooling properties of the material on the basis of crushed foam glass and determination of its extinguishing characteristics with the attitude to alcohols // Materials Science Forum, 1006 MSF, 2020, 62-69. doi: 10.4028/www.scientific.net/MSF.1006.62

3. Dadashov I., Loboichenko V., Kireev A. Analysis of the ecological 250 
characteristics of environment friendly fire fighting chemicals used in extinguishing oil products // Pollution Research. 2018. V. 37/1. P. 63-77. URL: https://www.scopus.com/inward/record.uri?eid=2-s2.085062144705\&partnerID=40\&md5=36a1aa2ad65f6325a5bac590a1deb977

4. Dadashov I., Kireev A., Kirichenko I., Kovalev A., Sharshanov A. Simulation of the insulating properties of two-layer material // Functional Materials. 2018. V. 25/4. P. 774-779. doi: 10.15407/fm25.04.774

5. Skorodumova O., Tarakhno O., Chebotaryova O., Hapon Y. Formation of fire retardant properties in elastic silica coatings for textile materials // Materials Science Forum, 1006 MSF. 2020. P. 25-31. doi: 10.4028/www.scientific.net/MSF.1006.25

6. Chernukha A., Kovaliov P., Ponomarenko S., Yeriomenko V. Research of fireproof properties of fabric for Fireproof rescue stretchers // Проблеми надзвичайних ситуацій. 2017.2 № $25 . \quad$ С. $149-152$. URL: http://repositsc.nuczu.edu.ua/handle/123456789/2706

7. Babrauskas V., Williamson R. The historical basis of fire resistance testing // $\begin{array}{lllll}\text { Fire } & \text { Technology } & \text { II. } & 1980 . & \text { P. }\end{array}$ URL: https://link.springer.com/article/10.1007/BF01998390

8. Brinker C. Y., Keefer K. D., Schaefer D. W. Sol-gel transition in simple silicates. J. Non-Cryst. Solids. 1982. V. 48(1). P. 47-64. doi: 10.1016/00223093(82)90245-9

9. Chernukha A., Teslenko A., Kovaliov P., Bezuglov O. Mathematical Modeling of Fire-Proof Efficiency of Coatings Based on Silicate Composition / Materials Science Forum. 1006. 2020. P. 70-75. doi: 10.4028/www.scientific.net/MSF.1006.70

10. Chopenko N., Muravlev V., Skorodumova O. Technology of molding masses for architectural and artistic ceramics using low-aluminate clays. International Journal of Engineering and Technology(UAE). 2018. V. 7(3). P. 587-590. URL: https://www.sciencepubco.com/index.php/ijet/article/view/14595/5944

\author{
A. Chernukha, PhD, Associate Professor of the Department \\ P. Kovalov, PhD, Associate Professor, Head of Department \\ O. Bezuglov, PhD, Associate Professor, Associate Professor of the Department \\ National University of Civil Defence of Ukraine, Kharkiv, Ukraine
}

\title{
ANALYSIS OF THE QUALITY OF APPLICATION OF IMPREGNATING FIRE PROTECTIVE AGENT DSA FOR OAK WOOD
}

In this work, experimental studies of the fire-retardant efficiency of the DSA agent for oak wood have been carried out. The dependence of the fire retardant efficiency on the mass of the dry agent was obtained, applied, which is important when processing oak wood with DSA. The influence of the characteristics of wood of various species on the effectiveness of fire-retardant impregnating agents was investigated using the example of oak and DSA agents. It has been established that the standard method of studies of fire retardant efficiency using exclusively pine cannot provide fair data on the effectiveness of the agent in other types of wood. So, according to the instructions of the means that the subject, 3 applications are necessary, but for oak to achieve the 1st group of fire retardant efficiency, 7 applications were required. After the study of the fireretardant efficiency of the DSA is provided in the norms for the example of oak wood processing, the fireresistance of other types of wood can be analyzed. In the course of previous studies, the fire retardant characteristics of the main fire retardants for some types of wood have already been obtained. Species of wood with a high density have poor impregnation, as a result of which more treatments are required to achieve the 1st group of fire retardant efficiency. The resulting dependence of the weight loss of a treated wood sample on the amount of fire retardant composition during standard tests makes it possible to perform engineering, economic and other calculations when performing works on fire protection. Tested standard fire retardant performance testing method using pine exclusively. It has been determined that standard test methods cannot be objective when processing species other than pine. Particularly useful for research is the dependence of the Civit security. DOI: 10.52363/2524-0226-2021-33-19 
weight loss of a treated wood sample on the amount of fire retardant composition during standard tests, the effect of the characteristics of wood of various species on the effectiveness of fire retardant impregnating agents on the example of oak and DSA agents. Oak has a higher specific gravity than pine, so it is more difficult to add a sufficient amount of active ingredient.

Keywords: fire protection, fire retardant efficiency, fire retardant coating, impregnation, experimental research

\section{References}

1. Chernukha, A. A., Kireyev, A. A., Bondarenko, S. N., Kirichenko, A. D. (2009). Issledovaniye ognezashchitnoy effektivnosti pokrytiy na osnove kserogelevoy kompozitsii. Pozhezhna bezpeka, 26, 166-171. Retrieved from http://repositsc.nuczu.edu.ua/handle/123456789/4551

2. Kireev, A., Tregubov, D., Safronov, S., Saveliev, D. (2020). Study insulating and cooling properties of the material on the basis of crushed foam glass and determination of its extinguishing characteristics with the attitude to alcohols. Materials Science Forum, 1006 MSF, 62-69. doi: 10.4028/www.scientific.net/MSF.1006.62

3. Dadashov, I., Loboichenko, V., Kireev, A. (2018). Analysis of the ecological characteristics of environment friendly fire fighting chemicals used in extinguishing oil products. Pollution Research, 37/1, 63-77. Retrieved from https://www.scopus.com/inward/record.uri?eid=2-s2.0-

85062144705\&partnerID=40\&md5=36a1aa2ad65f6325a5bac590a1deb977

4. Dadashov, I., Kireev, A., Kirichenko, I., Kovalev, A., Sharshanov, A. (2018). Simulation of the insulating properties of two-layer material. Functional Materials, 25/4, 774-779. doi: 10.15407/fm25.04.774

5. Skorodumova, O., Tarakhno, O., Chebotaryova, O., Hapon, Y., Emen, F.M. (2020). Formation of fire retardant properties in elastic silica coatings for textile materials. Materials Science Forum, 1006 MSF, 25-31. doi: 10.4028/www.scientific.net/MSF.1006.25

6. Chernukha, A., Kovaliov, P., Ponomarenko, S., Yeriomenko, V. (2017). Research of fireproof properties of fabric for Fireproof rescue stretchers. Problems of Emergency Situations, 25, 149-152. Retrieved from http://repositsc.nuczu.edu.ua/handle/123456789/2706

7. Babrauskas, V., Williamson, R. (1980) The historical basis of fire resistance testing. Fire Technology, II, 304-314. Retrieved from https://link.springer.com/article/10.1007/BF01998390

8. Brinker, C. Y., Keefer, K. D., Schaefer, D. W. (1982). Sol-gel transition in simple silicates. J. Non-Cryst. Solids, 48(1), 47-64. doi: 10.1016/0022-3093(82)90245-9

9. Chernukha, A., Teslenko, A., Kovaliov, P., Bezuglov, O. (2020). Mathematical Modeling of Fire-Proof Efficiency of Coatings Based on Silicate Composition. Materials Science Forum, 1006, 70-75. doi: 10.4028/www.scientific.net/MSF.1006.70

10. Chopenko, N., Muravlev, V., Skorodumova, O. (2018). Technology of molding masses for architectural and artistic ceramics using low-aluminate clays. International Journal of Engineering and Technology (UAE), 7(3), 587-590. Retrieved from: https://www.sciencepubco.com/index.php/ijet/article/view/14595/5944

Надійшла до редколегіï: 04.03.2021

Прийнята до друку: 13.04.2021 